DOI: https://doi.org/10.34069/AI/2021.42.06.3

How to Cite:

Pinkovetskaia, I.S., Yakhyaev, M.A., Laptev, S.V., \& Lipatova, N.N.. (2021). Awareness of the economically active population about entrepreneurship: country analysis. Amazonia Investiga, 10(42), 24-30. https://doi.org/10.34069/AI/2021.42.06.3

\title{
Awareness of the economically active population about entrepreneurship: country analysis
}

\section{Информированность экономически активного населения о предпринимательстве: анализ по странам}

Received: May 3, 2021

\begin{abstract}
Aim of study is to assess level of awareness for economically active population about modern entrepreneurship and its socio-economic significance. A survey of the economically active population on ways to obtain information about the activities of entrepreneurs in 59 countries served as the initial information of the study. Our research was aimed at evaluating indicators that describe the proportion of men and women who received information about entrepreneurship from the media, as well as from familiar entrepreneurs, in whole number gender groups. In course of research, economic and mathematical models were developed. The study showed that in most countries, the economically active population is more focused on business data from the media. It is shown that there is a gender gap in the level of people's awareness of entrepreneurship.
\end{abstract}

Keywords: entrepreneurship, mass media, men, women, awareness of entrepreneurship.

\section{Introduction}




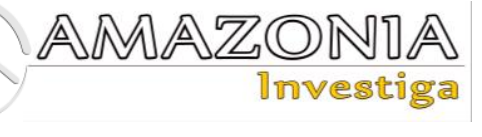

Entrepreneurship in most economically developed and developing countries solves a wide range of social problems. Along with providing themselves and their employees with jobs, entrepreneurs form a middle class and increase their social status (Borbás, 2015; Pinkovetskaia et al., 2020; Morgan \& Sisak, 2016; Pinkovetskaia et al., 2021a; Muller et al., 2017; Zahra \& Wright, 2016; Kiseleva et al., 2019).

One of the most pressing problems in the development of modern entrepreneurship is to attract new people to create their own businesses. To solve this problem, people should have whole information about the essence of entrepreneurship, the advantages and disadvantages of this activity, the qualities and competencies that successful entrepreneurs should have, the features of creating and operating businesses in the country where they live. It is known that the three main channels through which such information can be obtained are training in higher and secondary specialized educational institutions for training entrepreneurs, mass media (open sources), as well as direct acquaintance with entrepreneurs. Given that the majority of the economically active population uses the second and third channels, our article examines the opinions of such people about whether they receive information about entrepreneurship from open sources or from familiar entrepreneurs in their countries. The issues of obtaining relevant information by people have found a certain reflection in modern scientific publications (Colombo et al., 2017; Neumann, 2020; PejicBach et al., 2018; Tsai et al., 2016).

Taking into account the increasing role of gender studies in entrepreneurship (Chhabra \& Karmarkar, 2016; Grosser \& Moon, 2019; Pinkovetskaia et al, 2021b; Sperber \& Linder, 2018), along with cross-country analysis, this article examines the existing differences in women's and men's access to information about entrepreneurship. In more early scientific researches, problem of gender characteristics of informing people about entrepreneurship in various states was not given enough attention.

In modern states, it is necessary to effectively inform the public about the importance of entrepreneurship as a strategy for the development of national economies. At the same time, an entrepreneurial approach to life should be encouraged, aimed at developing the relevant talents of the economically active population and considering entrepreneurship as a further career.
Therefore, the actual research problem studied in this paper is to determine the level of awareness of adults about entrepreneurship, including consideration of the gender aspects of this problem. Paper responds to calls in scientific publications to assess the levels of awareness of men and women who use different channels to obtain information about entrepreneurship, achievements and shortcomings in this sector of the economy. As well as checking whether the national economies show gender differences in the research problem under consideration.

Aim of our paper is to assess awareness of the economically active population in various states about modern entrepreneurship. At the same time, the tasks of evaluating the indicators that characterize the two channels of obtaining relevant information - the mass media and familiar entrepreneurs-were solved.

\section{Methodology and design}

The initial information used in our study is the data obtained from the implementation of the Global Entrepreneurship Monitor project (2019). Surveys of at least two thousand representatives of the economically active population (EAP) in 59 states allowed us to find out the opinions of people, how they received information about entrepreneurship.

Our research consists of five stages. Stage 1 was associated with formation of initial data that describe opinions of the economically active population on these issues in different countries. The evaluation of the values of the shares (specific indicators) that characterize the specified opinions of women and men in whole number of these gender groups was carried out at the second stage. The third stage allowed us to determine not only the mean values of indexes, but also the limits in which values of these indexes are located in most states. The fourth stage was associated with a comparative analysis, which identified states with minimum and maximum values of indicators. Comparison of Russia and other countries we carry out at fifth stage.

Our study looked at the assessment of six indicators that characterize how women and men assessed the level of information received from the media and personal acquaintances in 2018. These indicators include:

- the part of women who believe that the mass media provides information about entrepreneurship, in the total amount of 
women in EAP;

- the part of men who believe that the mass media provides information about entrepreneurship, in the total amount of men in EAP;

- the relation of the values of indicators that characterize the availability of information about entrepreneurship in the mass media, according to women and men;

- the part of women who have information from personally known entrepreneurs in the total amount of women in EAP;

- the part of men who have information from personally familiar entrepreneurs in the total amount of men in EAP;

- the relation of the values of indicators that characterize the opinions of women and men who have information from personally familiar entrepreneurs.

Research included testing five hypotheses:

- hypothesis 1 - in most states, there is a gender gap in the opinions of people who believe that the media provides information about entrepreneurship;

- hypothesis 2 - in most states, there is a gender gap in the opinions of people who have information from personally familiar entrepreneurs;

- hypothesis 3 - there are significant differences in people's opinions about how to obtain information about entrepreneurship across different states;

- hypothesis 4 - on discussing indexes does not affect geographical position of states;

- hypothesis 5 - on discussing indexes does not affect the level of income people in states.

Assessment data on six considered indicators is relying on economic-mathematical modeling of the initial practical information. As such models we use density functions of normal distribution and such methodic for development is used for evaluating data on the indicators in the paper (Pinkovetskaia \& Slepova, 2018).

\section{Results of research}

Our calculations are made with economicmathematical modeling. Functions (y) show distributions variables $(\mathrm{x}, \%)$ in 59 states are below:

- the part of women who believe that the mass media provides information about entrepreneurship, in the total amount of women in EAP

$y_{1}\left(x_{1}\right)=\frac{674.28}{12.64 \times \sqrt{2 \pi}} \cdot e^{-\frac{\left(x_{1}-61.77\right)^{2}}{2 \times 12.64 \times 12.64}}$

- the part of men who believe that the mass media provides information about entrepreneurship, in the total amount of men in EAP;

$$
y_{2}\left(x_{2}\right)=\frac{632.14}{12.33 \times \sqrt{2 \pi}} \cdot e^{-\frac{\left(x_{2}-60.82\right)^{2}}{2 \times 12.33 \times 12.33}}
$$

- the relation of the values of indexes which characterize availability of information about entrepreneurship in the mass media, according to women and men

$$
y_{3}\left(x_{3}\right)=\frac{15.73}{0.33 \times \sqrt{2 \pi}} \cdot e^{-\frac{\left(x_{3}-1.06\right)^{2}}{2 \times 0.33 \times 0.33}}
$$

- the part of women who have information from personally known entrepreneurs in the total amount of women in EAP

$$
y_{4}\left(x_{4}\right)=\frac{516.25}{10.80 \times \sqrt{2 \pi}} \cdot e^{\frac{-\left(x_{4}-34.67\right)^{2}}{2 \times 10.80 \times 10.80}}
$$

- the part of men who have information from personally familiar entrepreneurs in the total amount of men in EAP

$$
y_{5}\left(x_{5}\right)=\frac{557.23}{12.04 \times \sqrt{2 \pi}} \cdot e^{\frac{-\left(x_{5}-42.58\right)^{2}}{2 \times 12.04 \times 12.04}}
$$

- the relation of the values of indexes which characterize opinions of women and men who have information from personally familiar entrepreneurs

$$
y_{6}\left(x_{6}\right)=\frac{5.16}{0.10 \times \sqrt{2 \pi}} \cdot e^{-\frac{\left(x_{6}-0.82\right)^{2}}{2 \times 0.10 \times 0.10}}
$$




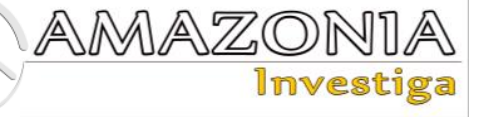

The quality of functions (1)-(6) we tested using such criteria: by the Kolmogorov-Smirnov, the Pearson and the Shapiro-Wilk.

\section{Discussion}

Based on functions (1)-(6) we have an

Table 1.

Indexes that characterize people's opinions about the availability of information about entrepreneurs

\begin{tabular}{|c|c|c|}
\hline Indicator & Mean indexes & $\begin{array}{l}\text { Most states } \\
\text { values }\end{array}$ \\
\hline 1 & 2 & 3 \\
\hline $\begin{array}{l}\text { the part of women who believe that the mass media provides information } \\
\text { about entrepreneurship, in the total amount of women in EAP, } \%\end{array}$ & 61.77 & 49.13-74.41 \\
\hline $\begin{array}{l}\text { the part of men who believe that the mass media provides information } \\
\text { about entrepreneurship, in the total amount of men in EAP, \% }\end{array}$ & 60.82 & $48.49-73.15$ \\
\hline $\begin{array}{l}\text { the relation of the values of indexes which characterize availability of } \\
\text { information about entrepreneurship in the mass media, according to } \\
\text { women and men }\end{array}$ & 1.06 & $0.73-1.39$ \\
\hline $\begin{array}{l}\text { the part of women who have information from personally known } \\
\text { entrepreneurs in the total amount of women in EAP, } \%\end{array}$ & 34.67 & $23.87-45.47$ \\
\hline $\begin{array}{l}\text { the part of men who have information from personally familiar } \\
\text { entrepreneurs in the total amount of men in EAP, } \%\end{array}$ & 42.58 & $30.54-54.62$ \\
\hline $\begin{array}{l}\text { the relation of the values of indexes which characterize opinions of } \\
\text { women and men who have information from personally familiar } \\
\text { entrepreneurs }\end{array}$ & 0.82 & $0.72-0.92$ \\
\hline
\end{tabular}

The average share of women who believe that the media provides data on entrepreneurship in the total number of adult women reached almost $61.8 \%$ in 2018 . The corresponding figure for men was slightly less $-60.8 \%$. That is, the values of the average values differ by less than $2 \%$. In general, the data in table 1 show that in the countries under review, the relative majority of the adult population (almost two-thirds) believes that the media provides data on entrepreneurship.

Twenty-six states are characterized by an excess of men's awareness of entrepreneurship from the mass media, compared with similar indicators for women. In six states, indexes for women and men were almost equal. In twenty-seven states, indexes for women were higher than for men. Thus, hypothesis 1 that there is a gender gap in the opinion of women and men in most countries that open sources provide information about entrepreneurship has been confirmed. The average value of relation of indexes for women and men in the countries under consideration was 1.06 in 2018.

The average share of women with information from personally familiar entrepreneurs in the number of adult women reached almost $34.7 \%$ in 2018. The corresponding figure for men was 1.2 times higher - almost $42.6 \%$. In most states, there is a trend of a higher value of this indicator for men. Exceptions were observed in three states - opportunity to define the number of regularities describing variants of getting information on entrepreneurship in the considered states. Mean indexes are in second graph of Table 1. Graph 3 of this table describes ranges change of indexes for most states.
Vietnam, Kazakhstan and Taiwan, in which indexes for women and men were almost the same. The average value of the relation of indexes was 0.82 in 2018. Thus, hypothesis 2 was confirmed that in most states there is a gender gap between women and men who have information from personally familiar entrepreneurs.

The data in table 1 show that in the states under consideration, a relative minority of the adult population has information from personally familiar entrepreneurs. Accordingly, the relative majority of the population does not have such information on the states under consideration.

It should be noted that women, in comparison with men, rate the availability of information about business activities from open sources higher. At the same time, men are more likely than women to receive similar information from familiar entrepreneurs. In our opinion, this is due to the fact that in many states men bigger than women are in entrepreneurship.

To test hypothesis 3 , data presented in graph 3 of first table were analyzed. The analysis showed significant differences in all indexes for discussing states. This gives opportunity to conclude about confirmation of third hypothesis.

States in which maximum and minimum indexes 
were discovered on fourth stage. High values, which more than higher border indicated in graph 3 of first table and lower values which less than their smaller borders (table 2). Except with

Table 2.

States with maximum and minimum values of indexes names of states, second table shows a subdivision of states by their geographic place and income of population.

\begin{tabular}{|c|c|c|}
\hline Indexes & Maximum & Minimum \\
\hline 1 & 2 & 3 \\
\hline $\begin{array}{l}\text { the part of women who } \\
\text { believe that the mass } \\
\text { media provides } \\
\text { information about } \\
\text { entrepreneurship, in the } \\
\text { total amount of women } \\
\text { in EAP }\end{array}$ & $\begin{array}{l}\text { Sudan, Bosnia and Herzegovina, Turkey, } \\
\text { Morocco, Angola, Germany, Canada, } \\
\text { Uruguay, Guatemala. There are two } \\
\text { countries in Europe, one state each in } \\
\text { Asia and North America, two states in } \\
\text { Latin America, and three states in Africa. } \\
\text { Income in these states: big - two, mean - } \\
\text { four, small - three. }\end{array}$ & $\begin{array}{l}\text { South Africa, Latvia, Republic of Korea, } \\
\text { Madagascar, Iran, Vietnam, India, } \\
\text { Mexico, United Kingdom, Japan. Two } \\
\text { countries are located in Europe, five in } \\
\text { Asia, two in Africa, and one in Latin } \\
\text { America. Four States have high incomes, } \\
\text { two States have medium incomes, and } \\
\text { four States have low incomes. }\end{array}$ \\
\hline $\begin{array}{l}\text { the part of men who } \\
\text { believe that the mass } \\
\text { media provides } \\
\text { information about } \\
\text { entrepreneurship, in the } \\
\text { total amount of men in } \\
\text { EAP }\end{array}$ & $\begin{array}{l}\text { Saudi Arabia, USA, Switzerland, } \\
\text { Madagascar, Israel, India, Germany, } \\
\text { Spain, Netherlands, Thailand. Four states } \\
\text { are located in Europe and Asia, as well as } \\
\text { North America and Africa, one state } \\
\text { each. The income of the population is } \\
\text { high in seven states, low-in three states. }\end{array}$ & $\begin{array}{l}\text { Croatia, Republic of Korea, Morocco, } \\
\text { Puerto Rico, Latvia, Argentina, Ireland, } \\
\text { Italy. Four states are located in Europe, } \\
\text { one state each is located in Asia and } \\
\text { Africa, and two states are located in Latin } \\
\text { America. Income in these states: big - six, } \\
\text { mean and small one for each. }\end{array}$ \\
\hline
\end{tabular}

the relation of the values of indicators that characterize the availability of information about entrepreneurship in the mass media, according to women and men

the part of women who have information from personally known entrepreneurs in the total amount of women in EAP

Argentina, Canada, China, Croatia, Estonia, Turkey, Angola, Russian Federation, Morocco, Uruguay. Three states are located in Europe, in Asia, Africa and Latin America, two states each, and in North America-one state. Income of the population: high (three states), medium (five states), low (two states).

Peru, Madagascar, Angola, Israel, Panama, Kazakhstan, Sudan, Vietnam, Indonesia, Saudi Arabia. There are five States in Asia, three States in Africa, and two States in Latin America. Income in these states: big - three, mean - two, small - five.

Peru, Israel, Panama, Angola, Lebanon,

the part of men who have information from personally familiar entrepreneurs in the total amount of men in EAP

the relation of the values of indicators that characterize the opinions of women and men who have information from personally familiar entrepreneurs
Vietnam, Sudan, Indonesia, Saudi Arabia. There are five States in Asia, and two states each in Latin America and Africa. Three states have high incomes, five states have low incomes, and one state has medium incomes.

Panama, Latvia, Ireland, China, Madagascar, Indonesia, Saudi Arabia, Vietnam, Kazakhstan, Taiwan. There are six States in Asia, one each in Africa and Latin America, and two in Europe. Income in these states: big - five, mean two, small -three.
South Africa, India, Iran, Madagascar, Spain, Thailand, Vietnam. One of these states is located in Europe, two States in Africa, and four States in Asia. High and medium incomes of the population occurred in one state, low incomes were in five states.

Egypt, Japan, Puerto Rico, Turkey, Greece, Italy, Germany. Three states are located in Europe, two States in Asia, and one state each in Latin America and Africa. High incomes of the population are observed in five states, medium and low incomes in one state.

Egypt, Puerto Rico, Japan, Germany, Greece, UAE, Italy. Three states are located in Europe, one state each in Latin America and Africa, and two states are located in Asia. Income of the population: high (six states), low (one state).

Egypt, Turkey, Italy, Iran, India, Greece, Brazil. Two of these States are located in Europe, three States in Asia, Africa and Latin America each have one State. Two States had high incomes, two States had medium incomes, and three States had low incomes. 


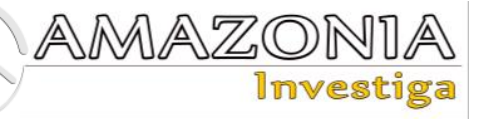

Table 2 provides data on geographic place of states with maximum and minimum values for nine indexes assessed in our research. Analysis of this data shows that we have no evident relationship between such values and geographic place of states and income of people in these states. That is, both maximum and minimum values of indexes are discussed in states placed in various parts of the world and disparity of population income. Thus we proved the accuracy of the fourth and fifth hypotheses.

A comparative analysis of the values of the considered indicators for Russia and foreign countries showed the following:

- first index is $72.1 \%$, that is 1.2 times higher than mean for other states;

- $\quad$ second index is $50.5 \%$, that is 1.2 times less than mean for other states;

- $\quad$ third index is 1.4 , that is 1.3 times higher than mean for other states;

- $\quad$ fourth index is $32.8 \%$, that is 1.1 times less than mean for other states;

- $\quad$ fifth index is $38.8 \%$, that is 1.1 times less than mean for other states;

- $\quad$ sixth indicator is 0.85 , that is slightly more than mean for other states.

Thus, in Russia, women are more likely than in other countries to draw information about entrepreneurship from the mass media. For men, the situation is the opposite. Women and men in Russia receive less information from their business acquaintances than in other countries. This is logical, since the share of entrepreneurs in Russia is significantly lower than in most foreign countries.

\section{Conclusions}

Aim of the study, which was to assess awareness of the economically active population about entrepreneurship in modern national economies according to data for 2018, was achieved. The novelty and originality of our research is related to the following aspects:

1. It is proved that, on average, in the countries under consideration, almost $62 \%$ of adult women believe that they receive information about entrepreneurial activities through the use of the media.

2. It is proved that, on average, in the countries under consideration, almost $61 \%$ of adult men believe that they receive information about entrepreneurial activities through the use of the media.
3. It is shown that almost two-thirds of the adult population agree with the thesis about the availability of information about entrepreneurship in the mass media.

4. It is proved that, on average, in the countries under consideration, almost $35 \%$ of adult women believe that they receive information about entrepreneurial activities from familiar entrepreneurs.

5. It is proved that, on average, in the countries under consideration, almost $43 \%$ of adult men believe that they receive information about entrepreneurial activities from familiar entrepreneurs.

6. It is shown that in most states, adults receive information about entrepreneurship to a greater extent from the mass media and to a lesser extent from familiar entrepreneurs.

7. The values of indicators that characterize the receipt of information about entrepreneurship in most states differ for women and men, that is, there is a gender gap.

8. In the states reviewed, there were large differences in the values of each of the six indices.

9. States with the maximum and minimum values of the indices were identified.

10. It is shown that the values of the indices are not affected by the geographical location of the states.

11. It is shown that the values of the indices are not affected by the level of income of people in the states under consideration.

The results of our work have a certain theoretical and practical significance for governments and entrepreneurs. The methodological approach presented in the article to assess the awareness of adult entrepreneurship can be used in further research. Of interest is the new knowledge gained as a result of our research, which is related to people getting information about entrepreneurship. This knowledge can be used both by potential entrepreneurs and in the educational process at universities.

The study had limitations on empirical data due to the fact that only 59 countries were considered.

\section{References}

Borbás, L. (2015). The Role of SMEs in the European Entrepreneurship Policy. Volume of Management, Enterprise and Benchmarking in the 21st Century II. Óbuda University, Keleti Faculty of Business and Management, 71-88. Chhabra, M., \& Karmarkar, Y. (2016). Gender gap in entrepreneurship - a study of small and micro enterprises. ZENITH International 
Journal of Multidisciplinary Research, 6(8), 82-99.

Colombo, L., Dawid, H., Piva, M., \& Vivarelli, M. (2017). Does easy start-up formation hamper incumbents' R\&D investment? Small Business Economics, 49, 513-531.

Global Entrepreneurship Monitor 2018/2019. (2019). Women's Entrepreneurship Report. Global Entrepreneurship Research Association (GERA). London Business School, London, United Kingdom.

Grosser, K., \& Moon, J. (2019). CSR and feminist organization studies: towards an integrated theorization for the analysis of gender issues. Journal of Business Ethics, 155(2), 321-342. https://doi.org/10.1007/s10551-0173510-x.

Kiseleva, O., Lebedev, A., Pinkovetskaia, I., Rojas-Bahamón, M., \& Arbeláez Campillo, D. (2019). Specialization and concentration of small and medium enterprises employees: Russian data. Amazonia Investiga, 8(20), 6-15. https://amazoniainvestiga.info/index.php/amazo nia/article/view/59

Morgan, J., \& Sisak, D. (2016). Aspiring to succeed: A model of entrepreneurship and fear of failure. Journal of Business Venturing, 31(1), 1-21.

Muller, P., Julius, J., Herr, D., Koch, L., Peycheva, V., \& Mckiernan, S. (2017). Annual Report on European SMEs 2016/2017. SME Performance Review. European Union. Directorate-General for Internal Market, Industry, Entrepreneurship and SMEs. https://www.researchgate.net/publication/32126 8021.

Neumann, T. (2020). The impact of entrepreneurship on economic, social and environmental welfare and its determinants: a systematic review. Management Review Quarterly, 70(3), 1-32.

Pejic-Bach, M., Aleksic, A., \& Merkac-Skok, M. (2018). Examining determinants of entrepreneurial intentions in Slovenia: applying the theory of planned behaviour and an innovative cognitive style. Economic Research, 31(1), 1453-1471.

Pinkovetskaia, I., Arbeláez-Campillo, D., RojasBahamón, M., \& Veas Iniesta, D. (2020). Motivation of new entrepreneurs in modern economies. Amazonia Investiga, 9(29), 368-373. https://doi.org/10.34069/AI/2020.29.05.41

Pinkovetskaia, I., Arbeláez-Campillo, D. F., Rojas-Bahamón, M. J., \& Sverdlikova, E. (2021a). Entrepreneurship for the elderly in Russia: situation and prospects. Amazonia Investiga, 10(39), https://doi.org/10.34069/AI/2021.39.03.9

Pinkovetskaia, I., Berezina, N., Navasardyan, A., \& Neif, N. (2021b). Gender aspects of entrepreneurs' motivation in modern countries. Amazonia Investiga, 10(39), 218-224. https://doi.org/10.34069/AI/2021.39.03.21

Pinkovetskaia, I.S., Kostina, T.I., \& Berezina, N.V. (2020). Evaluation of indicators of entrepreneurial potential in 2018. Amazonia Investiga, $\quad 9(27), \quad$ 173-179. https://amazoniainvestiga.info/index.php/amazo nia/article/view/1225

Pinkovetskaia, I., \& Slepova, V. (2018). Estimation of Fixed Capital Investment in SMEs: the Existing Differentiation in the Russian Federation. Business Systems Research, 9(1). 65-78. https://doi.org/10.2478/bsrj-2018-0006.

Sperber, S., \& Linder, C. (2018). Genderspecifics in startup strategies and the role of the entrepreneurial ecosystem. Small Business Economics, 53(4), 1-14. https://doi.org/10.1007/s11187-018-9999-2.

Tsai, K.-H., Chang, H.-C., \& Peng, C.-Y. (2016). Refining the Linkage between perceived capability and entrepreneurial intention: roles of perceived opportunity, fear of failure, and gender. International Entrepreneurship Management Journal, 10. 1-19.

Zahra, S., \& Wright, M. (2016). Understanding the Social Role of Entrepreneurship. Journal of Management Studies, 53(4), 610-629. 